\title{
Mudanças no padrão de alimentação da populacão urbana brasileira (1962-1988)
}

\author{
Changing diet patterns in Brazil (1962-1988)
}

\author{
Lenise Mondini*, Carlos A. Monteiro**
}

MONDINI, L. \& MONTEIRO, C.A. Mudanças no padrão de alimentação da população urbana brasileira (1962-1988). Rev. Saúde Pública, 28: 433-9, 1994. Objetivoul-se avaliar o comportamento do padrão alimentar da população urbana brasileira ao longo das três últimas décadas. As fontes de dados foram duas pesquisas nacionais de orçamentos familiares realizadas no início da década de 60 (1961-63) e no final da década de 80 (1987-88) e um inquérito nacional sobre consumo alimentar realizado em meados da década de 70 (1974-75), restringindo-se a análise a sete áreas metropolitanas estudadas em comum pelas três pesquisas. O padrão alimentar foi caracterizado a partir da participação relativa de diferentes alimentos na dieta e do consumo relativo de nutrientes específicos. As mudanças principais mostraram-se semelhantes nas regiões Nordeste e Sudeste e envolveram: 1) redução no consumo relativo de cereais, feijão, raízes e tubérculos; 2) substituição de banha, toucinho e manteiga por óleos e margarinas; e 3) aumento no consumo relativo de leite e derivados e ovos. Essas mudanças deterninaram diminuição na participação relativa de carboidratos na dieta e aumento na participação de lipídios. A proporção total de proteínas manteve-se estável entre as pesquisas (ao redor de $12 \%$ ), crescendo, entretanto, a participação específica de proteínas de origem animal na dieta. Situação inversa foi observada com os lipídios, registrando-se aumento da fração correspondente aos lipídios de origem vegetal, o que levou ao predomínio dos ácidos graxos poliinsaturados sobre os saturados e à redução do consumo relativo de colesterol. As implicações das mudanças no padrão alimentar da população urbana do país são discutidas à luz de recomendações dietéticas enunciadas pela Organização Mundial de Saúde.

Descritores: Conduta na alimentação. Hábitos alimentares. População urbana.

\section{Introdução}

Através de uma dieta adequada em quantidade e qualidade o organismo adquire a energia e os nutrientes necessários para o bom desempenho de suas funções e para a manutenção de um bom estado de saúde. De longa data, conhecem-se os prejuízos decorrentes quer do consumo alimentar insuficiente - deficiências nutricionais - quer do consumo alimentar excessivo - obesidade.

Mais recentemente, experimentos e estudos observacionais têm evidenciado estreita relação entre características qualitativas da dieta e ocorrência de enfermidades crônico-degenerativas,

\footnotetext{
* Núcleo de Pesquisas Epidemiológicas em Nutrição e Saúde da Universidade de São Paulo (NUPENS/USP)

- São Paulo, SP-Brasil

* Departamento de Nutrição da Faculdade de Saúde Pública da Universidade de São Paulo e do NUPENS/ USP - São Paulo, SP - Brasil

Separatas/Reprints: C.A.Monteiro - Av. Dr. Arnaldo, 715 -01246- 904 - São Paulo, SP - Brasil

Edição subvencionada pela FAPESP. Processo 94/0500-0.
}

como as doenças cardio-vasculares, o diabetes mellitus não insulino-dependente, diferentes tipos de câncer e mesmo a obesidade ${ }^{24}$. São exemplos clássicos a associação entre o consumo de gorduras saturadas e a ocorrência de doença coronaria$\mathrm{na}^{21}$ e o consumo de gordura de origem animal e a ocorrência de câncer de cólon, próstata e mamas ${ }^{25}$.

Ainda envolvendo a composição lipídica da dieta, há evidências de que a obesidade possa se relacionar à proporção de energia proveniente de gorduras, independentemente do total calórico da dieta ${ }^{20}$. De outro lado, há igualmente evidências de que dietas ricas em legumes, verduras e frutas cítricas encontram-se associadas à ocorrência menor de alguns tipos de câncer, como os de pulmão, cólon, esôfago e estômago. Embora os mecanismos subjacentes à associação não estejam completamente esclarecidos, sabe-se que essas dietas são usualmente pobres em gordura saturada e ricas em fibras e diversas vitaminas e minerais ${ }^{24}$.

O reconhecimento de que características da dieta possam exercer influência decisiva sobre o estado de saúde dos indivíduos determinou que a Organização Mundial de Saúde (OMS) estabele- 
cesse guias alimentares que definissem limites seguros para o consumo de gorduras, colesterol, açúcar, entre outros ${ }^{24}$.

De modo geral, a tendência da evolução de padrões dietéticos tem sido avaliada com base em dados sobre disponibilidade de alimentos. Esses dados, disponíveis para a maioria dos países, são compilados, anualmente, pela Organização das Nações Unidas para a Alimentação e Agricultura (FAO). Indicam a quantidade potencial média de alimentos disponível para consumo humano em cada país, considerando produção, importação e exportação de produtos alimentares e um percentual arbitrário de desperdício, sendo, na maioria das vezes, a única fonte regular e padronizada de informações sobre padrões alimentares. A interpretação desses dados deve ser feita com cautela, considerando a não possibilidade de se conhecer a distribuição do consumo nos diferentes estratos da população, a qualidade das estatísticas de produção e comercialização de alimentos em cada país e a imprecisão da conversão dos produtos alimentares em nutrientes ${ }^{10}$.

As Pesquisas de Orçamento Familiar (POFs) constituem fonte alternativa de informações sobre consumo alimentar, sendo este estimado através de despesas efetuadas com os alimentos e preços praticados no comércio. Quando realizadas com regularidade, propiciam a formação de séries temporais, essenciais para a identificação de mudanças em padrões de consumo alimentar. Além disso, as POFs permitem a desagregação de informações para estratos socioeconômicos e geográficos, possibilitando o estudo de grupos específicos da população. Entre as limitações das POFs destacam-se a ausência de informações sobre o consumo individualizado dos membros dos domicílios e, ainda, a impossibilidade de se avaliar a fração não aproveitada dos alimentos ${ }^{10}$.

Os inquéritos dietéticos, realizados através de diferentes metodologias, apresentam como principal vantagem a possibilidade da medida direta do consumo de alimentos, propiciando, assim, condições para se inferir com maior precisão a quantidade de alimentos efetivamente consumida por famílias ou mesmo indivíduos. Suas limitações ficam por conta da dificuldade em se captar a grande variabilidade do consumo alimentar em um período curto de tempo e o custo elevado do estudo domiciliar, que será tanto maior quanto maior for o tempo dedicado à observação do consumo.

Como nos demais países não desenvolvidos, são também escassas no Brasil as fontes de dados sobre consumo alimentar. Em nível nacional, o país conta com um único inquérito dietético realizado em meados da década de 70 e com duas POFs realizadas no início da década de 60 e no final da década de 80 . Especificamente para a cidade de São Paulo, dispõe-se de duas outras POFs realizadas no início das décadas de 70 e 80 . Utilizando informações provenientes das fontes de dados acima referidas, o presente artigo procurará resgatar, em grandes linhas, o que tem sido a trajetória da dieta brasileira ao longo das últimas décadas.

\section{Material e Método}

As caracteríticas principais das fontes de dados utilizadas no presente estudo estão descritas abaixo.

\section{Pesquisa de orçamento familiar - 1961/63}

Trata-se de pesquisa domiciliar de orçamento familiar executada pela Fundação Getúlio Vargas ${ }^{9}$ entre 1961 e 1963, envolvendo amostra probabilística de 9.125 domicílios, sendo 7.309 representativos das áreas urbanas das regiões Sul, Sudeste e Nordeste e 1.816 das áreas rurais dos Estados do Ceará, Pernambuco, Espírito Santo, Minas Gerais, São Paulo, Santa Catarina e Rio Grande do Sul. Mais da metade da amostra dos domić́lios urbanos (4.132) referem-se às famílias residentes nas seguintes capitais: Curitiba, São Paulo, Rio de Janeiro, Belo Horizonte, Salvador, Recife e Fortaleza. A quantidade de alimentos consumida no domicílio foi estimada a partir da divisão do gasto mensal declarado pelas famílias com cada tipo de alimento pelo preço médio dos produtos durante o período do inquérito (1961/62 para as capitais dos Estados e 1962/63 para outras áreas urbanas e para as áreas rurais). A quantidade de alimentos consumida dividida pelo número de pessoas no domicílio e pelo período de estudo fornece a estimativa do consumo médio per capita diário da família.

\section{Estudo Nacional da Despesa Familiar - ENDEF - 1974/75}

Trata-se de pesquisa domiciliar realizada pela Fundação Instituto Brasileiro de Geografia e Estatística (IBGE) 1975, envolvendo amostra probabilística de 55.000 domicílios de todo o país. Nessa pesquisa, o consumo médio per capita diário das famílias foi estimado, de forma direta, a partir do método de pesagem dos alimentos, aplicado por sete dias consecutivos em cada domicílio.

\section{Pesquisa de orçamento familiar - 1987/88}

Trata-se de pesquisa domiciliar de orçamento familiar executada pelo $\mathrm{IBGE}^{7}$ de março de 1987 a fevereiro de 1988, envolvendo uma amostra 
probabilística de 13.611 domicílios situados nas áreas metropolitanas de Porto Alegre, Curitiba, São Paulo, Belo Horizonte, Salvador, Recife, Fortaleza, Belém e em Goiânia e Brasília. A metodologia seguida para estimar o consumo médio per capita diário de alimentos foi semelhante à adotada pela POF -1961/63.

Opadrão alimentar conforme cada um dos inquéritos será caracterizado a partir da participação relativa dos diferentes alimentos (ou grupos de alimentos) na dieta e do consumo relativo (por $1.000 \mathrm{kcal}$ ) de carboidratos (simples ou complexos), proteínas (de origem animal ou vegetal) e lipídios (igualmente de origem animal ou vegetal). Adicionalmente será calculado o consumo relativo de ácidos graxos saturados, polinsaturados e de colesterol.

Os grupos de alimentos referidos são os cereais e derivados (arroz, fubá, farinha de trigo, pão, macarrão e bolachas); raízes, tubérculos e derivados (mandioca, farinha de mandioca e batatas); carnes (bovina, suína, aves e peixes); leite e derivados (leite "in natura", leite em pó e queijos) e frutas (laranja e banana).

A transformação de quantidades de alimentos em nutrientes foi feita com base na Tabela de Composição de Alimentos do ENDEF" e do "The Composition of Foods" 15 .

A análise da evolução dos padrões de consumo alimentar será restrita às áreas metropolitanas estudadas pelos três inquéritos, ou seja, Curitiba, São Paulo, Rio de Janeiro, Belo Horizonte, Salvador, Recife e Fortaleza*. Os resultados serão apresentados para o conjunto das áreas pertencentes à região Sudeste (São Paulo, Rio de Janeiro e Belo Horizonte) e à região Nordeste (Salvador, Recife e Fortaleza). As médias regionais de consumo foram obtidas ponderando-se as médias individuais de cada área metropolitana pela população estimada no momento dos inquéritos. As estimativas para o Brasil incluem a área metropolitana de Curitiba. Procedeu-se da mesma forma para calcular a média de consumo no conjunto das sete áreas metropolitanas, as quais, sem incluir Porto Alegre, Belém e Brasília, abragem cerca de 90\% do total da população metropolitana do país e mais de $1 / 4$ do total da população urbana brasileira.

Acredita-se que, na ausência de melhores estimativas, as mudanças observadas no padrão alimentar da população residente nas sete áreas estudadas possam indicar o comportamento do padrão alimentar da população urbana brasileira nas últimas três décadas.

\section{Resultados}

As mudanças no padrão alimentar, detectadas ao longo dos três inquéritos, mostram-se semelhantes para as populações urbanas do Sudeste e Nordeste do país e incluem: 1) redução do consumo de cereais e derivados, feijão, raízes e tubérculos, observada, principalmente, da década de 70 para a década de $80 ; 2$ ) aumento contínuo no consumo de ovos, leite e derivados; 3 ) substituição da banha, bacon e manteiga por óleos vegetais e margarina; 4) aumento no consumo de carnes, principalmente a partir da segunda metade da década de 70 (Tabela 1 ).

As modificações observadas determinam tendência generalizada de menor contribuição dos carboidratos no consumo calórico total e a sua substituição por gorduras, principalmente da década de

Tabela 1. Participação relativa (\%)de diferentes grupos de alimentos no consumo calórico total. Áreas metropolitanas brasileiras: 1962, 1975, 1988 .

\begin{tabular}{|c|c|c|c|c|c|c|c|c|c|}
\hline \multirow{2}{*}{ Alimentos } & \multicolumn{3}{|c|}{ Sudeste } & \multicolumn{3}{|c|}{ Nordeste } & \multicolumn{3}{|c|}{ Brasil } \\
\hline & 1962 & 1975 & 1988 & 1962 & 1975 & 1988 & 1962 & 1975 & 1988 \\
\hline Cereais e Derivados & 37,2 & 37,9 & 35,9 & 34,1 & 34,8 & 31,7 & 36,7 & 37,8 & 35,4 \\
\hline Feijāo & 7,2 & 8,8 & 6,2 & 9,1 & 9,9 & 7,7 & 7,6 & 8,9 & 6,4 \\
\hline Raízes e Tubérculos & 4,0 & 3,0 & 2,7 & 12,8 & 14,0 & 11,0 & 5,6 & 4,8 & 4,0 \\
\hline Carnes & 8,6 & 8,6 & 9,4 & 11,5 & 10,4 & 11,1 & 9,1 & 8,8 & 9,6 \\
\hline Ovos & 1,1 & 1,4 & 1,6 & 0,5 & 1,0 & 1,6 & 1,0 & 1,4 & 1,6 \\
\hline Leite e Derivados & 5,5 & 6,6 & 8,9 & 3,1 & 4,8 & 6,0 & 5,1 & 6,3 & 8,4 \\
\hline Frutas & 3,8 & 2,2 & 2,4 & 3,8 & 2,1 & 3,3 & 3,8 & 2,1 & 2,5 \\
\hline Banha/Touc./Mant. & 7,9 & 3,5 & 1,6 & 4,6 & 2,3 & 1,3 & 7,2 & 3,3 & 1,6 \\
\hline Margarina e Óleos & 8,9 & 13,6 & 17,0 & 4,7 & 6,1 & 10,8 & 8,1 & 12,3 & 16,0 \\
\hline Açúcar & 15,8 & 14,3 & 14,3 & 15,6 & 14,3 & 15,7 & 15,8 & 14,3 & 14,5 \\
\hline Total & 100,0 & 100,0 & 100,0 & 100,0 & 100,0 & 100,0 & 100,0 & 100,0 & 100,0 \\
\hline
\end{tabular}

* No primeiro inquérito (POF 1961/62), as áreas metropolitanas estiveram representadas exclusivamente pelos municípios-sede; de fato, as áreas metropolitanas brasileiras foram constituídas apenas na década de 70 ; nos outros dois inquéritos (ENDEF 1974/75 e POF 1987/88) a amostragem estendeu-se igualmente para os municípios periféricos das áreas metropolitanas. 
Tabela 2. Participação relativa (\%) de carboidratos, proteínas e lipídios no consumo calórico total. Áreas metropolitanas brasileiras: 1962, 1975, 1988.

\begin{tabular}{lccccccccc}
\hline Regiōes & \multicolumn{3}{c}{ Carboidratos } & \multicolumn{3}{c}{ Proteínas } & \multicolumn{3}{c}{ Lipídios } \\
Metropolitanas & 1962 & 1975 & 1988 & 1962 & 1975 & 1988 & 1962 & 1975 & 1988 \\
\hline Sudeste & 60,9 & 60,0 & 56,4 & 11,9 & 12,7 & 12,8 & 27,2 & 27,3 & 30,8 \\
Nordeste & 67,4 & 66,9 & 62,4 & 12,2 & 13,4 & 13,2 & 20,4 & 19,7 & 24,4 \\
\hline Brasil & 62,1 & 61,2 & 57,4 & 11,9 & 12,8 & 12,8 & 26,0 & 26,0 & 29,8 \\
\hline
\end{tabular}

70 para a década de 80 . A participação das proteínas na dieta pouco se altera ao longo de todo o período de estudo (Tabela 2).

A Tabela 3 fornece elementos adicionais sobre a tendência do consumo alimentar da população urbana do país. Observa-se que o açúcar compõe cerca de $1 / 4$ do total de carboidratos da dieta nos três inquéritos, havendo muito pouca variação entre as regiões Nordeste e Sudeste. A tendência ao consumo de proteínas de origem animal é crescente nas duas regiōes, subindo 1 a 2 pontos percentuais do primeiro (1962) para o segundo inquérito (1975) e 8 a 10 pontos percentuais do segundo (1975) para o terceiro inquérito (1988).

As maiores mudanças, no entanto, são observadas quanto ao consumo de gorduras. Evidenciase substancial progressão do consumo de gorduras vegetais em detrimento de gorduras de origem animal. A relação gordura vegetal/gordura animal que era, para o conjunto das cidades estudadas, de $4: 6$ no primeiro inquérito, passa para $5,5: 4,5$ no segundo inquérito e para 4:6 no terceiro inquérito.

Observa-se que na região Sudeste a redução no consumo relativo de gorduras de origem animal é mais intensa do primeiro para o segundo inquérito; na região Nordeste a redução é igualmente intensa ao longo dos três inquéritos.

A Tabela 4 mostra a evolução, no país, de características selecionadas da dieta ao lado de recomendações estabelecidas pela Organização Mundial de Saúde (OMS).

Preocupa constatar que: o consumo relativo de gorduras na região Sudeste, acusado pelo inquérito mais recente (1988), já ultrapassa o limite máximo recomendado pela Organização Mundial de Saúde; o consumo excessivo de açúcar está presente nos três inquéritos e em todas as áreas estudadas; e o consumo insuficiente de carboidratos complexos é evidenciado desde o inquérito de 1962 na região Sudeste e revelado na região Nordeste pelo último inquérito (1988).

Os aspectos positivos das mudanças na dieta referem-se ao aumento generalizado no consumo de ácidos graxos poli-insaturados, de tal forma que se verifica a inversão de sua relação com os ácidos graxos saturados. Observa-se, para região Sudeste, tendência decrescente no consumo de colesterol dietético.

\section{Discussão}

A comparação de três inquéritos domiciliares, ao longo de um período de 26 anos, aponta mudanças significativas na composição da dieta da população urbana do país.

As características do primeiro (1962) e do último (1988) inquérito impedem que se conheça a quantidade absoluta de alimentos consumida pelas famílias, tão somente permitindo a avaliação da participação relativa de cada alimento na dieta familiar. Neste sentido, pode-se dizer da adequação da composição da dieta familiar, mas não da adequação da quantidade de alimentos consumida pelas famílias.

Não há qualquer evidência de que a adequação do consumo energético total das famílias tenha se deteriorado ao longo da realização dos três inquéritos. Ao contrário, o fato de que tenha havido constante aumento no consumo relativo de produtos de origem animal - os mais apreciados e os de maior custo relativo -sugere que a adequação

Tabela 3. Consumo de nutrientes, segundo a origem. Áreas metropolitanas brasileiras: 1962, 1975, 1988.

\begin{tabular}{|c|c|c|c|c|c|c|c|c|c|}
\hline \multirow{2}{*}{ Nutrientes } & \multicolumn{3}{|c|}{ Sudeste } & \multicolumn{3}{|c|}{ Nordeste } & \multicolumn{3}{|c|}{ Brasil } \\
\hline & 1962 & 1975 & 1988 & 1962 & 1975 & 1988 & 1962 & 1975 & 1988 \\
\hline $\begin{array}{l}\text { Carboidratos } \\
\text { - Complexos } \\
\text { - Açúcar }\end{array}$ & $\begin{array}{l}100,0 \\
74,0 \\
26,0\end{array}$ & $\begin{array}{l}100,0 \\
76,1 \\
23,9\end{array}$ & $\begin{array}{c}100,0 \\
74,7 \\
25,3\end{array}$ & $\begin{array}{c}100,0 \\
76,8 \\
23,2\end{array}$ & $\begin{array}{l}100,0 \\
78,6 \\
21,4\end{array}$ & $\begin{array}{c}100,0 \\
74,7 \\
25,3\end{array}$ & $\begin{array}{c}100,0 \\
74,5 \\
25,5\end{array}$ & $\begin{array}{l}100,0 \\
76,6 \\
23,4\end{array}$ & $\begin{array}{l}100,0 \\
74,7 \\
25,3\end{array}$ \\
\hline Proteinas & 100,0 & 100,0 & 100,0 & 100,0 & 100,0 & 100,0 & 100,0 & 100,0 & 100,0 \\
\hline $\begin{array}{l}\text {-Animal } \\
\text { - Vegetal }\end{array}$ & $\begin{array}{l}47,8 \\
52,2\end{array}$ & $\begin{array}{l}49,4 \\
50,6\end{array}$ & $\begin{array}{l}57,1 \\
42,9\end{array}$ & $\begin{array}{l}45,6 \\
54,4\end{array}$ & $\begin{array}{l}46,6 \\
53,4\end{array}$ & $\begin{array}{l}56,1 \\
43,9\end{array}$ & $\begin{array}{l}47,8 \\
52,2\end{array}$ & $\begin{array}{l}48,7 \\
51,3\end{array}$ & $\begin{array}{l}56,5 \\
43,5\end{array}$ \\
\hline Lipídios & 100,0 & 100,0 & 100,0 & 100,0 & 100,0 & 100,0 & 100,0 & 100,0 & 100,0 \\
\hline $\begin{array}{l}\text { - Animal } \\
\text { - Vegetal }\end{array}$ & $\begin{array}{l}60,0 \\
40,0\end{array}$ & $\begin{array}{l}43,2 \\
56,8 \\
\end{array}$ & $\begin{array}{l}37,9 \\
62,1 \\
\end{array}$ & $\begin{array}{l}64,3 \\
35,7 \\
\end{array}$ & $\begin{array}{l}54,4 \\
45,6 \\
\end{array}$ & $\begin{array}{l}45,0 \\
55,0\end{array}$ & $\begin{array}{l}60,7 \\
39,3 \\
\end{array}$ & $\begin{array}{l}45,4 \\
54,6 \\
\end{array}$ & $\begin{array}{l}39,3 \\
60,7 \\
\end{array}$ \\
\hline
\end{tabular}


Tabela 4. Participação relativa (\%) de nutrientes selecionados no consumo calórico total. Áreas metropolitanas brasileiras: 1962, 1975, 1988.

\begin{tabular}{|c|c|c|c|c|c|c|c|c|c|c|}
\hline \multirow{2}{*}{ Nutrientes } & \multicolumn{3}{|c|}{ Sudeste } & \multicolumn{3}{|c|}{ Nordeste } & \multicolumn{3}{|c|}{ Brasil } & \multirow{2}{*}{$\begin{array}{l}\text { Recomendaçōes } \\
\text { OMS }^{*}\end{array}$} \\
\hline & 1962 & 1975 & 1988 & 1962 & 1975 & 1988 & 1962 & 1975 & 1988 & \\
\hline Lipídios & 27,2 & 27,3 & 30,8 & 20,4 & 19,7 & 24,4 & 26,0 & 26,0 & 29,8 & $(15 \% \cdot 30 \%)$ \\
\hline - Ácidos Graxos & & & & & & & & & & \\
\hline $\begin{array}{l}\text { Saturados } \\
\text { - Ácidos Graxos }\end{array}$ & 7,7 & 6,9 & 7,4 & 5,3 & 4,9 & 5,8 & 7,3 & 6,6 & 7,0 & $(0-10 \%)$ \\
\hline Polinsaturados & 6,5 & 8,4 & 10,0 & 3,8 & 4,2 & 6,3 & 6,0 & 7,7 & 8,8 & $(3 \%-7 \%)$ \\
\hline Colesterol & 205,9 & 166,0 & 165,2 & 154,9 & 128,2 & 147,7 & 195,7 & 158,5 & 160,8 & $(0.300 \mathrm{mg} / \mathrm{dia})$ \\
\hline Carboidratos & 60,9 & 60,0 & 56,4 & 67,4 & 66,9 & 62,4 & 62,1 & 61,2 & 57,4 & $(55 \%-75 \%)$ \\
\hline $\begin{array}{l}\text { - Complexos } \\
\text { - Açúcar }\end{array}$ & $\begin{array}{l}45,1 \\
15,8\end{array}$ & $\begin{array}{l}45,7 \\
14,3\end{array}$ & $\begin{array}{l}42,1 \\
14,3\end{array}$ & $\begin{array}{l}51,8 \\
15,6\end{array}$ & $\begin{array}{l}52,6 \\
14,3\end{array}$ & $\begin{array}{l}46,6 \\
15,8\end{array}$ & $\begin{array}{l}46,4 \\
15,8\end{array}$ & $\begin{array}{l}46,9 \\
14,3\end{array}$ & $\begin{array}{l}42,9 \\
14,5\end{array}$ & $\begin{array}{c}(50 \%-70 \%) \\
(0-10 \%)\end{array}$ \\
\hline Proteinas & 11,8 & 12,7 & 12,8 & 12,2 & 13,4 & 13,2 & 11,9 & 12,8 & 12,8 & $(10 \%-15 \%)$ \\
\hline
\end{tabular}

* Os valores entre parênteses correspondem aos limites de consumo propostos pela Organização Mundial de Súde ${ }^{24}$.

calórica das dietas evoluiu favoravelmente no período*. A expressiva redução na prevalência da deficiência energética em crianças e adultos, indicada pela comparação de estimativas obtidas em 1975 e em 1989, fala, também, a favor da melhoria na adequação calórica das dietas ${ }^{16,17}$.

A tendência brasileira de reduzir o consumo de cereais e tubérculos, de substituir carboidratos por lipídios e de trocar proteínas vegetais por proteínas animais, repete situação verificada, em décadas passadas, em diversos países desenvolvidos" e, mais recentemente, em países em desenvolvimento ${ }^{19}$.

Há evidências para os países desenvolvidos de que mudanças, como as descritas para o Brasil, estiveram associadas ao aumento da obesidade e de diferentes doenças crônico-degenerativas ${ }^{18,22,23}$. Com relação particularmente à obesidade, nota-se que o aumento de sua prevalência nos EUA, entre os anos de 1910 e 1976, ocorreu em paralelo ao aumento da proporção relativa de gorduras na dieta $e$ independentemente da elevação do consumo calórico total ${ }^{2}$.

No Brasil, no período decorrido entre o segundo e o terceiro inquérito, registrou-se elevação expressiva na proporção de adultos obesos ${ }^{17}$. As estimativas calculadas para as áreas metropolitanas revelam que esse aumento foi de $50 \%$ a $70 \%$ (Tabela 5).

$\mathrm{O}$ aumento na proporção de lipídios acarreta aumento no rendimento energético das dietas, o que, em determinadas situações pode ser considerado útil, como por exemplo no caso da prevenção da desnutrição infantil associada a dietas com baixa densidade energética ${ }^{13}$.

A tendência brasileira com relação à substituição de gorduras animais por gorduras vegetais foge a tendência observada, em décadas passadas, nos países desenvolvidos, que apresentavam comportamento exatamente inverso.

A singularidade da experiência brasileira, neste caso, deveu-se, sobretudo, ao virtual abandono do consumo de banha de porco e toucinho e sua substituição por óleos vegetais, em particular o óleo de soja. Do primeiro para o terceiro inquérito, o consumo energético relativo de banha e toucinho caiu de $4,9 \%$ para $1,0 \%$, enquanto que o mesmo consumo de óleos subiu de $7,7 \%$ para $13,5 \%$. Também importante foi a substituição da manteiga pela margarina: entre o primeiro e o terceiro inquérito, o consumo de manteiga caiu de $2,2 \%$ para $0,6 \%$ e o de margarina subiu de $0,4 \%$ para $2,5 \%$.

A elevação do consumo relativo de carnes deu-se, exclusivamente, por conta do aumento no

Tabela 5. Prevalência de adultos (25-64 anos) com obesidade (IMC >30 Kg/m²). Regióes metropolitanas, 1974 e 1989 .

\begin{tabular}{lcccccc}
\hline Regióes & \multicolumn{2}{c}{ Homens } & \multicolumn{2}{c}{ Mulheres } & \multicolumn{2}{c}{ Total } \\
\cline { 2 - 7 } Metropolitanas & ENDEF & PNSN & ENDEF & PNSN & ENDEF & PNSN \\
& 1974 & 1989 & 1974 & 1989 & 1974 & 1989 \\
\hline Sudeste & 4,6 & 7,1 & 10,1 & 15,5 & 7,5 & 11,6 \\
Nordeste & 3,4 & 5,8 & 7,9 & 12,3 & 5,9 & 9,3 \\
\hline Brasil & 4,5 & 6,9 & 9,8 & 15,2 & 7,3 & 11,4 \\
\hline
\end{tabular}

Fontes: IBGE - Estudo Nacional da Despesa Familiar (ENDEF), 1974/75. Dados inéditos.

IBGE/INAN - Pesquisa Nacional sobre Saúde e Nutrição (PNSN), 1988/89. Dados inéditos.

* Produtos de origem animal (carnes, leite e derivados e ovos) compuseram, respectivamente, $15,7 \%, 16,5 \% \mathrm{e}$
$19,6 \%$ do total calórico fornecido pelas dietas nos inquéritos de 1962, 1975 e 1988. 
consumo de aves, cuja proporção de gordura é menor do que a presente nas carnes vermelhas.

A alteração na composição da ingestão lipídica no Brasil é importante na medida em que determina aumento considerável no consumo relativo de ácidos graxos polinsaturados e relação mais favorável entre estes e os ácidos graxos saturados. Esta situação permite inferir efeitos benéficos sobre a incidência de algumas enfermidades crônicodegenerativas, em particular sobre a ateroesclerose ${ }^{3 *}$. Tal parece ter sido a ordem de grandeza na variação da relação polinsaturados/saturados, que não seria infundado atribuir-se à mesma algum papel na redução da mortalidade por doenças cardiovasculares que vem sendo apontada em cidades como São Paulo, Curitiba, Salvador, Fortaleza e Belém ${ }^{14}$.

A modificação favorável no consumo lipídico das dietas brasileiras não parece se ter dado pela conscientização dos indivíduos acerca dos benefícios que adviriam para sua saúde, a exemplo do que tem ocorrido em alguns países desenvolvidos ${ }^{8,10}$. De fato, o início das mudanças - provavelmente entre os anos 60 e os anos 70 , quando a relação dieta e saúde ainda não repercutia no Brasil - e a ausência de campanhas educativas sobre o assunto sugerem que se busque em outras esferas a explicação para as mudanças na dieta.

O comportamento da oferta e dos preços relativos dos produtos alimentares talvez seja o fator principal a explicar, no Brasil, tanto a substituição de cereais, feijão e tubérculos por óleos vegetais, quanto o predomínio das gorduras vegetais sobre as animais.

Tabela 6. Participação relativa (\%) de nutrientes selecionados no consumo calórico total. Município de São Paulo: 1962, 1971, 1981.

\begin{tabular}{lccc}
\hline \multirow{2}{*}{ Nutrientes } & \multicolumn{3}{c}{ Período } \\
\cline { 2 - 4 } & $1962^{*}$ & $1971^{\star \star}$ & $1981^{\star \star}$ \\
\hline Lipídios & 31,0 & 31,6 & 33,7 \\
Carboidratos & 58,5 & 56,2 & 55,3 \\
Proteínas & 10,6 & 12,2 & 10,9 \\
Açúcar & 13,6 & 14,4 & 15,3 \\
Lipídios de & & 12,5 & 9,3 \\
origem animal & 13,7 & & \\
Lipídios de & & 19,1 & 24,4 \\
origem vegetal & 17,2 & 19,2
\end{tabular}

* Getúlio Vargas Foundation".

**Fundaçãolnstituto de Pesquisas Econômicas (FIPE/USP) 8.12

* Recentemente, alguns estudos têm questionado a real proteção que determinados tipos de gordura vegetal exercem sobre a doença coronariana. $O$ aumento da disponibilidade de ácidos graxos "trans" formados pela hidrogenação parcial dos óleos vegetais, que ocorre na produção de margarinas, poderia reduzir os níveis séricos de lipoproteínas de alta densidade e aumentar os de baixa densidade ${ }^{25}$.
Dados sobre a disponibilidade interna de alimentos no Brasil apontam, por exemplo, que a disponibilidade de produtos como o arroz, o feijão e o trigo apresentou-se estagnada (ou em decréscimo) ao longo das décadas de 70 e 80 , enquanto que a disponibilidade de soja aumentou expressivamente 4 . Por outro lado, dados de uma série histórica sobre as variações de preços de alimentos na cidade de São Paulo mostram que, entre 1962 e 1975 , houve aumento nos preços relativos de feijão, cereais e derivados e diminuição nos preços de leite e ovos'.

As tendências de elevação no consuno relativo de gorduras e de substituição de gordura animal por gordura vegetal são confirmadas no Município de São Paulo pelas POFs realizadas pela Fundação Instituto de Pesquisas Econômicas da Universidade de São Paulo (FIPE/USP) no início das décadas de 70 e 80 (Tabela 6).

Outros aspectos da composição da dieta mereceriam ser investigados no Brasil, como é o caso da evolução da disponibilidade de fibras na dieta. Entretanto, os dados disponíveis não permitem avaliação precisa do problema, uma vez que as POFs não detalham, suficientemente, o consumo de hortaliças. Baseado, entretanto, na tendência de redução do consumo relativo de alimentos como feijão e cereais, e na manutenção do consumo elevado de açúcar, pode-se pressupor evolução não favorável para a ingestão de fibras.

Outros aspectos relacionados à evolução da dieta certamente deveriam ser investigados, como o consumo de álcool, o teor de sódio na alimentação, a presença de vitaminas antioxidantes e a concentração e biodisponibilidade de minerais como o ferro e o zinco. Tais aspectos, entretanto, apenas poderiam ser investigados caso se dispusessem de inquéritos delineados com o propósito específico de informar sobre a evolução do consumo alimentar da população. A execução periódica desses inquéritos e o estabelecimento de sistema de monitoramento da evolução de padrões dietéticos afiguram-se como claras prioridades para o país.

Registre-se a prioridade crescente que as autoridades sanitárias brasileiras deveriam consignar à relação dieta-saúde, seja implementando medidas que visem à conscientização da população para o problema, seja trabalhando junto a outros setores do governo no sentido de garantir a oferta de (e o acesso a) uma alimentação saudável para todos.

\section{Agradecimentos}

À Professora Sonia Tucunduva Philippi do Departamento de Nutrição da Faculdade de Saúde Pública da USP; ao Professor Heron Carlos Esvael 
do Carmo do Departamento de Economia da Faculdade de Economia e Administração da USP pela assessoria prestada quanto a particularidades metodológicas das Pesquisas de Orçamentos Familiares.

MONDINI, L. \& MONTEIRO, C.A. [Changing diet patterns in Brazil (1962-1988)]. Rev. Saúde Pública, 28: 433-9, 1994. Contemporary changes in food consumption patterns in urban areas of Brazil are described. The main data sources are two national food expenditure surveys undertaken in the early 60's and late 80's (1961-62 and 1987-88) and one national food intake survey undertaken in the mid-70's (1974-75). The analysis is restricted to the seven metropolitan areas represented in the three surveys. Food patterns are described on the basis of the relative consumption of different food groups, proportion of energy from carbohydrates, protein and lipids, proportion of animal and vegetable protein and fats, proportion of complex and simple carbohydrates, ratio between polyunsaturated and saturated fatty acids and relative consumption of cholesterol. Main food changes were similar in the Northeastern and Southeastern cities and involved: 1) reduction in the relative consumption of cereals, beans, roots and tubercles; 2) replacement of lard, bacon and butter by vegetable oils and margarine: and 3 ) increase in the relative consumption of eggs, milk and dairy products. As a net result of these changes there was, simultaneously, a decrease in the carbohydrate content of the Brazilian diet and an increase in its fat content. Total protein content of the diet remained at around $12 \%$ in the three surveys but animal protein increased. Changes in the fat content of the diet involved an increased proportion of vegetable fat, an increased ratio of poly-unsaturated/saturated fatty acids and a reduction in cholesterol intake. Health implications of dietary changes are discussed based on the World Health Organization's dietary guidelines.

Keywords: Feeding behavior. Food habits. Urban population.

\section{Referências Bibliográficas}

1. CARMO, H.C.E. Impacto nutricional da evolução dos precos dos alimentos em São Paulo. São Paulo, 1980. [Dissertação de Mestrado - Faculdade de Economia e Administração da USP].

2. DREON, M.D. et al. Dietary fat: carbohydrate ratio and obesity in middle-age men. Am. J. Clin. Nutr., 47: 995 . 1000,1988

3. FAO. Dietary fats and oils in human nutrition; report of an expert consultation. Rome, 1980. (FAO Food and Nutrition Series, 20).

4. FUNDACÃO GETÚLIO VARGAS. Balanço e disponibilidade interna de gêneros alimenticios de origem vegetal. Rio de Janeiro, 1991.

5. FUNDAÇÃO IBGE. Tabela de composição de alimentos. Rio de Janeiro, 1977. (Estudo Nacional da Despesa
Familiar - ENDEF, v.3: publicações especiais, t. 1).

6. FUNDAÇÃO IBGE. Consumo alimentar; antropometria. Rio de Janeiro, 1977. (Estudo Nacional da Despesa Familiar - ENDEF, v.1: dados preliminares, Regiões I, II, Ill, IV e V, t.1).

7. FUNDAÇÃO IBGE. Pesquisa do orçamentos familiares POF 1987/88. Rio de Janeiro, 1991, v.1.

8. FUNDAÇÃO INSTITUTO DE PESQUISAS ECONÔMICAS (FIPE). Pesquisas de orçamentos familiares. 1981/ 82. São Paulo, 1982.

9. GETULIO VARGAS FOUNDATION. Food consumption in Brazil: family budget survey in the early 1960's Jerusalem, Keter Press, 1970.

10. HELSING, E. \& BECKER, W. Food and health data: their use in nutrition policy making. Copenhagen. 1991 (WHORegional publications, European Series, 34).

11.JAMES, W.P.T. Health nutrition: preventing nutritionrelated diseases in Europe: Copenhagen, 1988 (WHO Reginal Office for Europe, European Series, 24).

12. KIRSTEN, J.T. et al. Orçamentos familiares na cidade de São Paulo, 1971/72. São Paulo, Instituto do Pesquisas Econômicas (IPE), 1973. (Série IPE/monografias, v. 3).

13. LJUNGOVIST, B.G. et al. Dietary bulk as a limiting factor for nutrient intake in pre-school children. J. Trop. Pediat., 27:68-73,1981

14.Lólio, C.A. Mortalidade por doenças do aparelho circulatório em capitais de regiōes metropolitanas do Brasil, 1979-1989. São Paulo, 1994. [Tese do LivreDocência-Faculdade de Saúde Pública da USP].

15.McCANCE, R. A. \& WIDDOWSON'S, E. M. The composition of foods. 5th ed.Cambridge, The Royal Society of Chemistry and Ministry of Agriculture, Fisheries and Food, 1991.

16. MONTEIRO, C.A. et al. Nutritional status of Brazilian children: trends from 1975 to 1989 . Bull. World Health Org., 70: 657-66,1992.

17. MONTEIRO, CA. et al. The nutrition transition in Brazil. Eur J. Clin.Nutr., 1994. [in press].

18. NATIONAL RESEARCH COUNCIL. Committee on Diet and Health, Food and Nutrition Board. Commission on Life Sciences. Diet and health: implications for reducing chronic disease risk. Washington, DC, National Academy Press, 1989.

19. POPKIN, B.M. Nutritional patterns and transitions. Popul. Develop. Rev., 19:138-57,1993.

20. ROMIEU, I. et al. Energy intake and other determinants of relative weight. Am. J. Clin. Nutr., 47:406-12,1988.

21. SLATERRY, M.L. \& RANDALL, D.E. Trends in coronary heart disease mortality and food consumption in the United States bettween 1909 and 1980. Am. J. Clin. Nutr., 47:1060-7, 1988.

22. STAMLER, J. Epidemic obesity in the United States. Arch Intern. Med., 153:1040-4,1993.

23. US DHHS. U.S. Department of Health and Human Services. Surgeon general's report on nutrition and health. Washington, DC, Public Health Service, U.S. Department of Health and Human Services, 1988.

24. WHO STUDY GROUP ON DIET, NUTRITION AND PREVENTION OF CHRONIC DISEASES. Geneva, 1989. Report. Geneva, World Health Organization, 1990 (WHO - Technical Report Series, 797).

25. WILLETT, W.C. Diet and health: what should we eat? Science, 264: 532-7, 1994.

Recebido para publicaçāo em 19.9.1994 Aprovado para publicação em 24.10 .1994 